\section{Integrative Medicine \\ International}

Integr Med Int 2017;4:69-84

This article is licensed under the Creative Commons Attribution-NonCommercial-NoDerivatives 4.0 International License (CC BY-NC-ND) (http://www.karger.com/Services/OpenAccessLicense). Usage and distribution for commercial purposes as well as any distribution of modified material requires written permission.

\title{
Yoga: Can It Be Integrated with Treatment of Neuropathic Pain?
}

\author{
Shirley Telles ${ }^{d, e} \quad$ Natasha Sayal $^{b}$ Carrie Nacht $^{a} \quad$ Abhishek Chopra $^{a}$ \\ Kush Patel $^{\mathrm{a}}$ Alice Wnuk ${ }^{\mathrm{a}}$ Priya Dalvi ${ }^{\mathrm{c}}$ Kulsajan Bhatia ${ }^{\mathrm{f}}$ \\ Gurwattan Miranpuria $^{a}$ Akshay Anand ${ }^{\mathrm{b}}$
}

a Department of Neurological Surgery, University of Wisconsin School of Medicine and Public Health, Madison, WI, USA; ${ }^{b}$ Department of Neurology, Postgraduate Institute of Medical Education and Research, Chandigarh, India; ' ${ }^{c}$ Department of Kinesiology, University

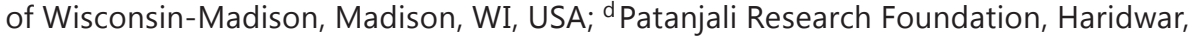
e Center for Advanced Research in Yoga and Neurophysiology, Indian Council of Medical Research, Bangalore, and ${ }^{f}$ Sector 32, Government Medical College, Chandigarh, India

Keywords

Spinal cord injury - Neuropathic pain - Pranayama - Asanas · Puraka - Kumbhaka .

Kapalabhati $\cdot$ Iyengar yoga $\cdot$ Ashtanga yoga

\begin{abstract}
Background: Neuropathic pain (NP) is a debilitating condition that may result from spinal cord injury (SCI). Nearly 75\% of all SCIs result in NP affecting 17,000 new individuals in the United States every year, and an estimated $7-10 \%$ of people worldwide. It is caused by damaged or dysfunctional nerve fibers sending aberrant signals to pain centers in the central nervous system causing severe pain that affects daily life and routine. The mechanisms underlying NP are not fully understood, making treatment difficult. Identification of specific molecular pathways that are involved in pain syndromes and finding effective treatments has become a major priority in current SCI research. Yoga has therapeutic applications that may prove beneficial in treating subjects suffering chronically from SCI-induced NP, chronic back and associated pain if necessary experimental data are generated. Summary: This review aims to discuss the implications of various mechanistic approaches of yoga which can be tested by new study designs around various nociceptive molecules including matrix metalloproteinases, cation-dependent chloride transporter (NKCC1), etc. in SCI-induced NP pa-
\end{abstract}

S.T. and N.S. contributed equally to this work.

Dr. Akshay Anand

Department of Neurology

Postgraduate Institute of Medical Education and Research Chandigarh (India)

E-Mail akshaylanand @ rediffmail.com
Dr. Gurwattan Miranpuri

Department of Neurological Surgery

University of Wisconsin School of Medicine and Public Health Madison, WI (USA)

E-Mail g.miranpuri@neurosurgery.wisc.edu 
tients. Key Messages: Yogic practices could be used in managing SCI-induced NP pain by regulating the action of various mechanisms and its associated molecules. Modern prescriptive treatment strategies combined with alternative approaches like yoga should be used in rehabilitation centers and clinics in order to ameliorate chronic NP. We recommend practical considerations of careful yoga practice as part of an integrative medicine approach for NP associated with SCI.

(C) 2017 The Author(s)

Published by S. Karger AG, Basel

\section{Introduction}

Following an injury to the spinal cord, functional impairment and pain syndromes are prominent and present a significant complication towards recovery. Spinal cord injury (SCI) is persistent worldwide, with an annual incidence up to 40 cases per million, with more than 17,000 cases each year in the United States alone [1]. Neuropathic pain (NP) is a common outcome following SCI occurring in up to $70 \%$ of SCI patients [2, 3]. Currently, no globally acceptable treatment exists for SCI-induced NP. The mechanisms behind the pain syndrome are not well understood due to its complexity and its likeliness to be induced by multiple causes. In addition to pain, the patient also experiences tremendous loss of function below the level of the lesion and quality of life. Yoga as an alternative medicine in rehabilitation has been shown to increase pain tolerance in SCI and other patients with pain [4,5]. The impact of yoga on SCI has not been officially documented as there are no known published studies of this work. Most of the yoga studies are confronted with methodological limitations especially with regard to the choice of control group and their nonblinded design. These limitations also apply to the majority of studies examining the effect of diet and exercise on disease management and wellness because human compliance to change in diet, exercise, or yoga is not easy to address.

"Yoga" (/jougə/) is an ancient Indian combination of a physical, mental, and spiritual practice. It is defined as a system of exercises for mental and physical health. In Hindu philosophy, the inner peace is achieved by controlling the body and mind functions. Further, in order to attain liberation and to achieve the supreme, yoga may help in achieving the mental control and well-being [6-10]. These studies show yoga is being practiced by several religious faiths like Hinduism, Jainism, and Buddhism, particularly Vajrayana Buddhism. The implication of yoga practice for insulin resistance syndrome, cardiovascular disease, and possible protection [11] as a complementary intervention for cancer [12] and schizophrenia [13], and as an alternative and complementary treatment for asthma [14] has been documented. In general, these studies suggest that yoga acts as a preventive measure and helps in patient's psychological healing process.

The term "yoga" has changed much since its arrival into our world. It is derived from the Sanskrit word yuj which means to unite, and it is an ancient Indian way of life. The main aim of yoga is to achieve holistic health by following the eightfold path of yoga. The 8 paths include yama (universal ethics for the moral and spiritual development), niyama (individual ethics), asana (physical postures for physical development), Pranayama (breath control for the improvement of physiological functions), pratyahara (control of the senses), dharana (concentration for making our mind alert and pointy), dyana, (meditation), and Samadhi (a bliss which helps in attaining inner peace) [15]. Different branches of yoga also exist which include Karma (path of service), Raja (path of meditation), Jnana (path of sage or scholar), bhakti (path of devotion), and Tantra (path of rituals). Also, there are various styles followed by different yoga practitioners like Hatha Yoga, Kundalini Yoga, Iyengar Yoga, Ashtanga Yoga, etc. 


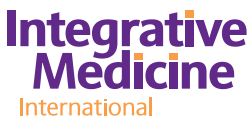

Internationa

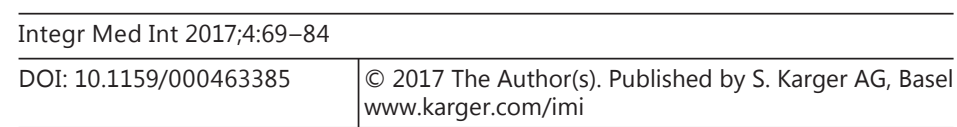

Telles et al.: Yoga: Can It Be Integrated with Treatment of Neuropathic Pain?

David Gordon White in 2014 described the Pranayama technique of controlling the body with regulated breathing [7]. There are always variations in practice but the main steps of this technique are consistent: (1) inhalation or inspiration, which in Sanskrit terminology is known as puraka which means filling up of lungs, (2) exhalation or expiration, which in Sanskrit is called rechaka meaning emptying the lungs, and (3) retention or holding the breath which is termed kumbhaka, a state where there is no inhalation or exhalation [16]. Regulation of breath affects the control of the autonomic nervous system, which further has beneficial effects on the different organs of the body. The autonomic nervous system is the involuntary response the body has to certain stimuli and is made up by the sympathetic and parasympathetic systems [17]. When Pranayama breathing is performed with long breath retention, the parasympathetic nervous system is amplified, resulting in lower metabolic rate and oxygen consumption. On the other hand, with brief breath retention there is an adverse result of augmented oxygen consumption and metabolic rate [18]. It is also observed that while performing "kapalabhati" yogic breathing (high-frequency breathing), there is exaggerated sympathetic activity, and during "nadisudhi" yogic breathing (Anulom Vilom or slow alternate nostril breathing), decreased sympathetic activity is observed. Since the autonomic nervous system is the primary control center of the cardiovascular system, a strong sympathovagal balance ensures its stability.

Yoga, a healing discipline which includes breath control, meditation, and adaptation of various specific body poses or asanas assists in relaxation and pain relief. Meta-analysis of yoga practice has been suggested as a possible alternative medicine intervention for patients with physical and psychosocial symptoms; however, breast cancer patients showed small effect size on functional wellness [19]. Various studies have noted improvement in sleep, mood, and quality of life (i.e., depression, emotional function, anxiety) among cancer patients [20-22]. These studies indicate how yoga may be helpful in relief of some symptoms associated with cancer; however, there is no known study on pain improvement in cancer patients. As stated by American Society of Cancer and NIH, yoga is believed to provide relief to cancer patients; however, there are no documented studies on the impact of yoga in alleviating the pain associated with malignancies and the effect it has on the overall well-being of cancer patients. Like cancer and other disorders, yoga may promote healing for SCI-induced NP by alleviating pain as it has shown promising results in the other pain disorders. Galantino et al. [23] have shown the impact of the modified Hath yoga practice in chronic low back pain. Results indicated the improvement in the balance and flexibility of the patients having low back pain, but a large trial is required. In another study on low back pain, Sherman et al. [24] found Viniyoga, which is a therapeutically oriented yoga school, more significant as compared to control group in diminishing the low back pain and pain-related disability. This defines the potential role yoga may play in the healing processes of NP.

\section{Chronic Pain in Relation to Environmental Factors}

A large body of evidence from the patients suffering with pain as well as associated animal models has revealed that chronic pain is not unifactorial but has many comorbidities and consequently may lead to anxiety, depression, and cognitive decline [25-30].

\section{Pathophysiology}

It is also observed that there is development of anxiety and depression among patients suffering from long-term pain, which results in the impairment of their cognitive functions, particularly working memory. Many studies suggest that nonpharmacological interventions can reduce the burden of chronic pain. Social and environmental manipulations have been 


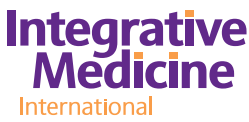

Internationa

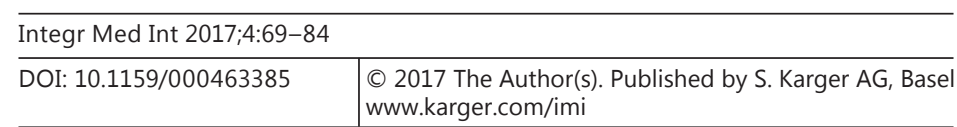

Telles et al.: Yoga: Can It Be Integrated with Treatment of Neuropathic Pain?

shown to influence NP. Environmental enrichment weakens both nerve injury-induced mechanical and cold hypersensitivity. It is also believed to lower the calcitonin gene-related peptide and concentration of substance P. On the other hand, an impoverished environment intensifies mechanical hypersensitivity [31]. Emerging targets like chemokines, Wht pathway, and proteases have been shown to increase spinal cord neuroinflammation and chronic pain [32]. Pro-resolution lipid mediators and anti-inflammatory mediators have also been implicated to work on glial cells, immune cells, and neurons and result in resolution of synaptic plasticity, neuroinflammation, and pain. Targeting the increased neuroinflammation could provide newer therapeutic opportunities for treatment of chronic pain and related neurological disorders. The pain can be classified on the basis of its mechanism into 5 main types: peripheral neuropathic, central sensitization, sympathetically maintained pain, nociceptive, and cognitive-affective [33]. The management and treatment of NP depends on the incidence and underlying pathologies. The conventional postherpetic neuralgia includes the use of topical lignocaine and anticonvulsants such as gabapentin and carbamazepine. Sodium channel blockers such as lidocaine, SSRI (selective serotonin reuptake inhibitors) such as venlafaxine and duloxetine, opioids such as morphine and fentanyl, and transdermal patches remain an expensive intervention with various side effects such as orthostatic hypotension, cardiac conduction defects, memory impairment, urinary retention, and sedation. Even the latest modalities such as transcutaneous electrical nerve stimulation, conduction blocks, decompression surgeries and spinal cord stimulation have failed to provide the relief. Moreover, their increased cost and long-term side effects call for an integrative approach which includes yoga [34, 35].

\section{Understanding the Molecular Mechanisms of NP}

NP following SCI is complex, and the mechanisms underlying such pain syndromes are not well understood. Traumatic SCI leads to changes in the expression of several genes with significant functional consequences. Different therapies for pain and functional impairment in both acute and chronic state following SCI are being explored. To develop a workable therapy, it is a necessity to identify the specific molecular pathways that are altered as a function of time, following SCI. Several mechanisms based on animal models have been implicated in SCI-induced NP; however, no practical relationship of these novel findings has been established with yoga practice. Various studies have described the role of several nociceptive molecules including matrix metalloproteinases (MMPs), cationdependent chloride transporter (NKCC1), CB1/CB2, bradykinin 1 (B1), and vanilloid receptor TRPV1. Authors have speculated, through various grant proposals, that by inhibiting upregulation of such pain molecules in the early phase and/or late phase of injury, spinal cord damage and induced NP could be ameliorated. Our research findings from previous studies have helped in understanding novel mechanisms and treatments for SCI and NP employing a rat model [36-42]. This review aims to prompt new studies that examine the possible relationship of nociceptive proteins and its implications in translational approach of yogic processes in NP.

\section{The Role of Cation-Dependent Chloride Transporter}

In our research group, we described Cl-regulatory protein $\mathrm{Na}^{+}-\mathrm{K}^{+}-\mathrm{Cl}^{-} 1$ (NKCC1) as a cation-dependent chloride transporter involved in NP following contusion SCI (cSCI) [43]. NKCC1 was inhibited by bumetanide in a rat model, which resulted in the implication of NKCC1 in postinjury response that suggested contribution to NP following cSCI. After administration of bumetanide to the subjects, thermal hyperalgesia (TH) and hind-paw withdrawal 
latency times were increased. A kinase known as the with-no-lysine (K)-1 (WNK1) is a regulator of NKCC1 activation by phosphorylation. In many systems, including nociception, mutations in this kinase with the neuronal-specific exon of WNK1 in patients with hereditary sensory neuropathy type II show that patients with a mutation in nociception have a lessened awareness to pain, touch, and heat. The overall implication of NKCC1 and its activating kinase WNK1 shows their contribution in sensing and developing NP [37]. It will be interesting to investigate the relationship between NKCC1 and WNK1 upregulation as it relates to yoga practice.

\section{Matrix Metalloproteinases}

Following NP, MMPs are triggered to be released both as early (MMP9) and late (MMP2) reactions. The release of these MMPs triggers inflammatory cytokines, which in turn results in NP after injury via interleukin-1 $\beta$-mediated activation in a spinal nerve ligation model of rat and mice. By using tissue inhibitors of MMPs and intrathecal injections of siRNAs, MMP levels are reduced, resulting in a decreased amount of inflammatory markers in comparison with wild-type mice [44]. Following induced cSCI in male adult Sprague-Dawley rats, we studied MMP2 in SCI-induced NP, the role of $\beta$-catenin in the WNT signaling pathway, and extracellular signaling kinase within the mitogen-activated protein kinase (MAPK) cascade [40].

\section{ATP Receptors}

These receptors exist in the peripheral as well as the central nervous system and could be implicated in pain signaling. ATP is discharged from cells following damage and activates sensors, which in turn activates sensory neurons. Therefore, these sensory neurons could be involved in sensing NP, such as the P2X4 receptors [44, 45]. A common response following nerve injury induced P2X4 in the ipsilateral spinal cord and induced hyperactive microglia. After administration of P2X4 antisense oligodeoxynucleotide, tactile allodynia was subdued from the depreciated activation of P2X4 receptors. To confirm this, the induction of P2X4 receptors increased tactile allodynia in a normal rat model [46]. Microglia are suggested intermediates in the pathway of induction of hypersensitivity following NP. The p38 MAPKs and P2X4 receptors are necessary molecules that are activated after peripheral nerve injury in the spinal cord [47]. ATP is believed to be involved in acute pain as it is released from all the injured cells and excites the initial sensory neurons by stimulating their receptors [45]. However, in sensory neurons or in the spinal cord, suppressing the expression of $\mathrm{P} 2 \mathrm{X} / \mathrm{Y}$ receptors by molecular targeting and blocking P2X/Y receptors pharmacologically did not show any improvement in acute physiological pain. Understanding the importance of ATP receptors including $\mathrm{P} 2 \mathrm{X} 4$ receptors may prove to be a cornerstone for newer strategies in NP management.

\section{Cannabinoid Receptors}

Hama and Sagen [48] report that by injecting the nonselective CB receptor agonist WIN 55,212-2 (WIN), SCI-induced mechanical allodynia following a thoracic-level compression SCI was reduced. The emerging role of AEA-specific fatty acid amide hydrolase and 2AG-specific monoacylglycerol lipase as regulators of catabolism and biosynthesis of the CBs is reported [49]. In our research group, pretreatment with CB-1 antagonist AM 251 had not affected the antihyperalgesic effect of WIN, while pretreatment with the CB-2 receptor antagonist AM 630 reduced the effect of WIN significantly, suggesting a modulating role of the CB receptor in SCI-induced TH [42]. Selectively activating the CB receptors and their possible therapeutic value for treating SCI patients has been discussed as a potential for analgesic effects on NP. 


\section{$B 1$ and TRPV-1 Receptors}

Following a rat CSCI model of NP in our lab, we have demonstrated that B1 and vanilloid (TRPV-1) receptor genes are highly expressed following injury of animals displaying TH in comparison to similarly injured animals without hyperalgesia [50]. In animals exhibiting hyperalgesia, a more than twofold increase in the expression of these 2 genes was detected in the epicenter region of the spinal cord when compared with animals with SCI that did not display hyperalgesia. This finding is consistent with other findings revealing contribution of B1 and vanilloid (TRPV1) receptors in nociception.

\section{Brain-Derived Neurotrophic Factor and Serotonin}

In certain animal models of chronic pain, brain-derived neurotrophic factor (BDNF) signaling contributed to central sensitization. By deleting trkB.T1, which is a spliced truncated isoform of the BDNF receptor tropomyosin-related kinase B.T1 in a mice model, there was a notable decrease in post-SCI locomotor dysfunction, mechanical hyperesthesia, and white matter loss. This suggests that the mechanism of SCI-induced chronic pain includes trkB.T1 in its cycle pathway [51].

\section{Astrocyte Contribution to Pain Signaling}

Glial cells in the spinal cord are important regulators of chronic pain. Specifically, astrocytes play a prominent role in the upregulation of signaling pathways that contribute to chronic pain. This is distinct from microglial mechanisms in that astrocyte activation is longer lasting and more persistent. Multiple chemokines, CCL2 and CXCL1, released by spinal cord astrocytes have been found to contribute to NP [52-54]. It is unclear how astrocytes regulate NP sensitization via the release of astrocytic mediators. CCI provoked the increase of astrocytic connexin-43 in spinal astrocytes. Three weeks after injury, mechanical allodynia can be reduced by intrathecal injection of carbenoxolone (CBX), a nonselective hemichannel blocker and selective connexin-43 blocker. TNF- $\alpha$ leads to the release of chemokine CXCL1, which is further blocked by CBX, connexin-43 small interfering RNA, and Gap26/Gap27. TNF- $\alpha-$ activated astrocytes induced persistent mechanical allodynia which is restrained by CXCL1 neutralization, antagonist CXCL1 receptor (CXCR2), and pretreated astrocytes with RNA of connexin-43. In nerve injury, there is an increase in excitatory synaptic transmission, which in a study by Gao and Ji [54] was suppressed by CBX and Gap27.

The hemichannel protein $\mathrm{Cx} 43$ provides a release portal for astrocyte mediators such as chemokines. After nerve injury, astrocyte junction signaling may switch from fast gap junctions to a slow paracrine route through $\mathrm{Cx} 43$ hemichannels. $\mathrm{Cx} 34$ contributes to pain hypersensitivity in a mouse with SCI. Additionally, Cx34 was shown to play a role in chronic pain maintenance after CCI. The intrathecal injection of CBX, a Cx43 blocker, was shown to weaken mechanical hypersensitivity after CCI. Electrophysiological experiments showed that spontaneous excitatory postsynaptic currents were higher in CCI models compared to controls, a result lowered by CBX or mimetic peptides [55].

\section{Spinal p38 MAPK}

Spinal p38 MAPK plays a crucial role in pain induced by inflammation, while activated spinal microglia plays a direct role in spinal nociceptive processing. As compared to posttreatment, pretreatment with p38 MAPK blocks spinal sensitization which is manifested by upregulation of cyclooxygenase-2 and appearance of Fos-positive neurons [56]. It has been suggested that the stimulation of the Src/p38MAPK signaling cascade gives rise to persistent mechanical hyperalgesia in late stages which is excited by formalin injection into the paw of the animal [57]. Furthermore, this unique finding is of significance for clinicians when developing therapeutic treatment during the acute and persistent pain states. 


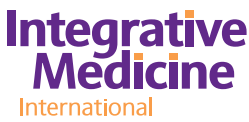

Internationa

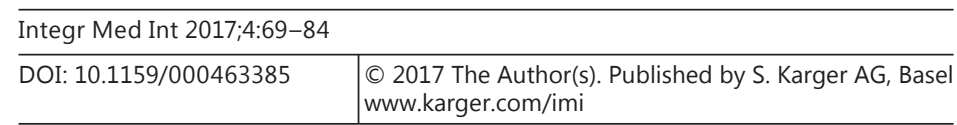

Telles et al.: Yoga: Can It Be Integrated with Treatment of Neuropathic Pain?

The Role of Glutamate Receptor-5 and Protein Kinase $C-\varepsilon$

The capsular ligament and cervical facet joint are the most common causes of neck pain which has been explored in in adults but not in adolescents. In one study, a bilateral C6-C7 facet joint distraction induced mechanical hyperalgesia 7 days after injury and significantly augmented protein kinase $C-\varepsilon$ expression in small- as well as medium-sized neurons. Postinjury MGluR5 expression was increased significantly in small-sized neurons, while activation of microglia was highest in naïve animals. Overall, the results showed that young individuals have a lower induced pain tolerance in comparison to adults [58].

\section{Management of Pain through Yoga}

\section{Insular Cortex Moderates Increased Pain Tolerance in Yoga Practitioners}

Today, yoga is being considered more often to treat painful conditions. Studies are in progress to investigate the possible neuroanatomical changes after practicing yoga and use sensory testing and magnetic resonance imaging techniques to test its benefits. One study has shown that North American yogis had more tolerance to pain as compared to individually matched controls [59]. This study also examined the effect of long-term and regular yoga practice on the experienced North American yogis as compared to the control and analyzed the thermal detections, pain thresholds, and cold pain tolerance in both groups. Analyses of the structural changes in the brain gray matter and white matter have revealed that yogis had increased left intrainsular white matter integrity as compared to controls and, due to their parasympathetic activation and increased awareness, they are able to tolerate more pain as compared to the control group.

\section{A Summary of Inquiries and Findings in Pain Management in Yoga Practitioners}

Studies compiled in Table 1 [60-63] describe the nonpharmacological management of pain. Despite the heterogeneity in the yoga intervention, all the studies have shown the improvement in the yoga practitioners group as compared to the control group. This may clearly indicate that the mind-body techniques are quite useful in the treatment of back pain or other types of pain.

\section{Meditation, Yoga, and Cognitive Behavioral Therapy}

Chronic pain is deemed to be an emerging problem of the modern world with many people suffering from back pain, headaches, and arthritis [64]. Since pharmacological treatment is not giving much relief, people are looking for other modalities in the form of mind-body therapies (MBT), including meditation, yoga, and cognitive behavioral therapy. Furthermore, MBT affect the neural mechanisms underlying the use of cognitive and emotional states for modulating the pain.

\section{Yoga as a Healing Approach for SCI}

The Potential of Yoga in Rehabilitation of SCI Patients

When disruption of the spinal cord occurs, the communication is affected in parts that are innervated at or below the lesion. Almost half of the spinal cord injuries are an outcome of motor vehicle crashes and the other half are due to falls or sports injuries, etc. Apart from the trauma, other factors responsible for the SCI are bleeding, swelling, and oxygen deprivation which are further accompanied by the release of toxic substances and inflammatory cytokines. Several neuroprotective agents, which include methylprednisolone, are being used as the treatment for spinal injuries and may prevent cell death. SCI is followed by several complications for which there is a need of rehabilitation [65]. Existing SCI centers are trying 
Table 1. A summary of inquiries and findings in pain management in yoga practitioners

\begin{tabular}{|c|c|c|}
\hline Topic & Inquiry & Findings \\
\hline $\begin{array}{l}\text { BDNF and } \\
\text { serotonin levels } \\
\text { with chronic back } \\
\text { pain [60] }\end{array}$ & $\begin{array}{l}\text { Premenopausal women with lower back pain } \\
\text { practiced yoga } 3 \text { times a week for } 12 \text { weeks } \\
\text { Back pain intensity was measured using visual } \\
\text { analog scale (VAS), serum BDNF, and serotonin } \\
\text { levels }\end{array}$ & $\begin{array}{l}\text { Marked decrease in back pain was seen in the yoga } \\
\text { group when compared with the control group } \\
\text { Serotonin levels remained constant in the yoga } \\
\text { group and reduced in the control group } \\
\text { Depression levels were greater in the control group } \\
\text { as compared to the yoga group } \\
\text { BDNF has beneficial effects on chronic back pain and } \\
\text { is key factor in yogis }\end{array}$ \\
\hline $\begin{array}{l}\text { Fibromyalgia with } \\
\text { pain measurement, } \\
\text { cortisol level } \\
\text { testing [61] }\end{array}$ & $\begin{array}{l}\text { Women with fibromyalgia took a } 75 \text {-min yoga } \\
\text { class twice a week for } 8 \text { weeks and were } \\
\text { assessed for their pain, psychological } \\
\text { functioning, mindfulness, and cortisol levels } \\
\text { Pain/anxiety/depression questionnaires were } \\
\text { subsequently filled out } \\
\text { The day before the start and after } 8 \text { weeks, } \\
\text { cortisol samples were collected } 3 \text { times a day }\end{array}$ & $\begin{array}{l}\text { Improvements in pain and mindfulness were } \\
\text { assessed via ANOVA } \\
\text { All improvements were significant } \\
\text { Median cortisol levels were higher after intervention } \\
\text { than before intervention } \\
\text { Yoga intervention may reduce pain and } \\
\text { catastrophizing, increase acceptance and } \\
\text { mindfulness, and alter total cortisol levels in women } \\
\text { with FM }\end{array}$ \\
\hline Chronic pain [62] & $\begin{array}{l}\text { Yoga's effect on perception of pain and } \\
\text { treatment of actual pain } \\
\text { Asanas and Pranayama trigger a relaxation } \\
\text { response in the body, which helps to calm the } \\
\text { hyperarousal state in chronic pain }\end{array}$ & $\begin{array}{l}\text { Hyperarousal of the nervous system which leads to } \\
\text { decreased muscle tension, more regular breathing, } \\
\text { higher energy levels, and more quality mindset } \\
\text { Help with emotional aspects of chronic pain, } \\
\text { reduction of anxiety and depression }\end{array}$ \\
\hline $\begin{array}{l}\text { Back pain, yoga } \\
{[63]}\end{array}$ & $\begin{array}{l}\text { Physical therapy for } 4 \text { weeks (frequency } \\
\text { per week not specified) or Wii yoga program } \\
\text { ( } 7 \text { different exercises) for } 30 \text { min, } \\
3 \text { times a week, for } 4 \text { weeks in female } \\
\text { participants with lower back pain }\end{array}$ & $\begin{array}{l}\text { Significant differences were observed in both groups } \\
\text { in algometer, VAS, Oswestry low-back pain disability } \\
\text { index, fear avoidance beliefs questionnaire scores, } \\
\text { and Roland-Morris Disability Questionnaire } \\
\text { Groups in the Wii yoga program showed decreased } \\
\text { differences in all tests }\end{array}$ \\
\hline
\end{tabular}

to incorporate and redevelop skills in SCI patients. Teams of nurses, physicians, psychologists, social workers, and physical and occupational therapists provide multidisciplinary services for rehabilitation of SCI patients, but the area of yoga as a therapy is unexplored in this field. Yoga is a holistic approach, which is believed to stimulate neural pathways and neurotransmitters. With proper adaptation and through guided assistance, different yogic techniques may act as a valuable healing tool in the regeneration of nerve fibers in SCI patients for which many research studies are being undertaken $[5,66]$.

The Role of Iyengar Yoga as a Treatment Therapy for SCI Patients

After SCI, the prevalence of sedentary lifestyle leads to secondary impairment and deterioration of the functional activities. For performing movements and overcoming the side effects of pharmacological approaches, SCI patients need special exercise programs, mindbody techniques and assisted guidance to overpower these problems. Existing evidence is available which shows that the Iyengar form of yoga is a boon for SCI patients. B.K.S. Iyengar introduced Iyengar yoga which empowers the strength, flexibility, and physical balance through stretching of muscles. The asanas in this style of yoga are modifiable and the use of props makes it more innovative. Some studies have provided instructions regarding the inte- 
Telles et al.: Yoga: Can It Be Integrated with Treatment of Neuropathic Pain?

gration of Iyengar yoga as rehabilitation for SCI patients [64]. According to these authors, the Iyengar form of yoga helps to empower the patient by building symmetric and asymmetric postures to gain flexibility and awareness of the body structure by integration of Pranayama into the postures and focuses on the weight and time management of muscle contraction and relaxation [67].

Asana, Pranayama, and Meditation in Other Dysfunctions of SCI

SCI patients suffer from many dysfunctions, including bowel, bladder, sexual, pain, and depression. To overcome and reduce loss, specific yogic forms and different limbs of yoga are believed to help. Evidence shows that yoga may help in the treatment of pain, depression, anxiety levels, brain metabolism, and neurotransmitters. Some researchers studied the reaction time after performing bellows type breathing and breath awareness. Reaction time was analyzed in 2 groups containing 35 participants, a yoga group and a control group, with a mean age of 29 years. The yoga group had a prior 6-month experience of yoga practice, while the control group was not involved in any kind of yoga practice. The yoga group was assessed in 2 sessions. The first was bellows breathing and the second was breath awareness. Assessments were made using a multioperational apparatus for reaction time. The results demonstrated a significant reduction in the number of anticipatory responses following $18 \mathrm{~min}$ of Bhastrika as compared to that before practice. This indicated that Bhastrika Pranayama might modify the responses to stimuli [68].

The analyses of the above arguments or pathologies are not meant to generate misleading recommendations of yoga being responsible for regeneration of nerve fibers in SCI. This should be viewed with caution, although an extensive review of the literature about spinal cord regeneration has been avoided in this paper.

\section{Yoga for Posttraumatic Stress Disorder}

Chronic pain patients show associated anxiety and depression, and various mind-body practices can alter pain and pain-related ailments $[69,70]$. Posttraumatic stress disorder (PTSD) is a chronic mental health condition that starts by witnessing or experiencing a terrifying event. People who acquire PTSD have difficulty adjusting to their daily activities and experience symptoms such as nightmares and severe anxiety. There is prevalence of PTSD after SCI [71]. Many people with PTSD do not fully recover and go through episodes of this condition through their lifetime. People who are most likely to be impacted are war veterans who have just witnessed the disturbing images surrounding war. Previous studies have shown the promising results in the management of PTSD by using complementary and alternative treatments $[72,73]$. The University of Wisconsin-Madison is testing a new treatment program for PTSD that does not involve drugs or traditional therapy. These scientists hypothesized that yoga and mindful breathing may help PTSD victims more effectively with the treatment of the disease. The Center for Investigating Healthy Minds at the University of Wisconsin is actively researching to gain the understanding of treatment through yoga.

\section{Effect of Yoga on Neurotransmitters}

Regular practice of yogic exercise has shown alteration of various neurotransmitters in the brain. One PET study showed that during yoga Nidra meditation increased endogenous dopamine release in the ventral striatum [74]. In another study, a 60-min yoga session increased the brain GABA levels as compared to controls performing a 60-min reading [75]. This study aimed to explore the practice of regular yoga as one of the strategies for the treating anxiety- and depression-related disorders. Furthermore, another study revealed that yogic practice daily for $1 \mathrm{~h}$ for a period of 3 months helps in lowering ACTH and cortisol, while elevating serotonin, dopamine, and BDNF in healthy active men [76]. 


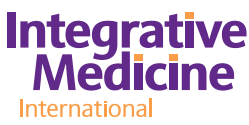

Integrative
Medicine

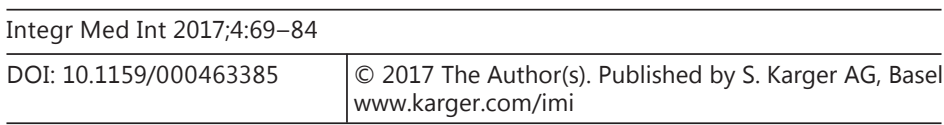

www.karger.com/imi

Telles et al.: Yoga: Can It Be Integrated with Treatment of Neuropathic Pain?

The Effect of Sudarshan Kriya Yoga on Depression and Anxiety

One group studied the response of P300 amplitude and antidepressant to Sudarshan Kriya yoga (SKY) [77]. They recruited 30 drug-free depressed patients and assessed them at 3 intervals: before treatment, after 1 month, and after 3 months. The antidepressant effects of SKY were measured through P300 ERP amplitude. Twenty-two patients responded well to the treatment which showed the effectiveness of SKY in depression. Another study involved 103 Swedish individuals, 55 in a Sudarshan Kriya and Pranayama group and 48 individuals in the control (a simply relaxed) group [78]. At the end of 6 weeks, participants in the Sudarshan Kriya and Pranayama group were found to have a lower degree of anxiety, depression, and stress compared to the control group. Another study demonstrated that serum BDNF levels change after practicing a yoga module consisting of loosening exercise, asana, Pranayama, and meditation [79]. This study had a total of 137 patients, aged 18-55, who were recruited and segregated into 3 groups. The first group $(n=23)$ received only yoga therapy, the second group $(n=78)$ received only medication, and the third group $(n=36)$ received yoga therapy and medication for 12 weeks. The results showed a significant decrease in Hamilton Depression Rating Scale scores of the 3 groups, but more reduction was observed in patients receiving a yoga session without medication as compared to the medication alone group. The patients suffering from depression reported antidepressant effects which were correlated with increased serum BDNF levels. Hamilton Depression Rating Scale score reduction and rise in BDNF levels were reported in the yoga only group [79].

\section{Yoga for Chronic Low Back Pain}

In 2 studies that examined the effects of yoga on chronic lower back pain, randomized control designs followed a 12-week yoga trial test group versus a control group [80, 81]. A total of 312 participants were randomized into 2 groups and were followed up at 3, 6, and 12 months. Females with a mean age of 46 years made up about $70 \%$ of the participants. In the other study, a 3-arm trial was performed [81]. A total of 229 participants were randomized into 3 different groups: self-care book, yoga, and active stretching intervention. Each group was led for 12 weeks by physical therapists. The participants of the yoga group showed significant improvement compared to the self-care group. However, yoga classes were not more effective compared to stretching classes in treating chronic low back pain.

A review about pain medicine for primary care providers has highlighted 6 topics including pain management by some intervention, NP, opioid dose and risk of overdose death, yoga for chronic low back pain, behavioral therapy and cognition, and treating back pain with evidence for the benefits. Overall, it discussed a systematic approach, the risks and limitations of the different modalities for treating chronic pain [82]. Additionally, other studies have suggested the benefits of yoga in treating a variety of pain conditions $[69,83]$. In both trials, participants were adults suffering from low back pain; they were instructed in a set of 12 -week yoga classes. A standardized protocol which includes physical postures, breathing, and relaxation exercises was considered. At the 3-month time point, pain was assessed by the Roland-Morris Disability Questionnaire score. Results indicated that this 12-week protocol for adults had improved lower back pain. In another study done in England, 851 participants were randomized into 2 groups: intervention group $(n=568)$ and control group $(n=283)$. The initial intervention was based on the 9-item Keele STaRT Back Screening Tool, in which subjects were divided based on low, medium, or high risk for persistent pain and disability. Patients at low-risk were excluded while medium- and high-risk patients were considered for standardized physical therapy to address symptoms and function. It was reported that a stratified approach has better implications for better management of back pain than a nonstratified approach [84]. 


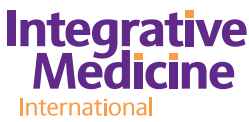

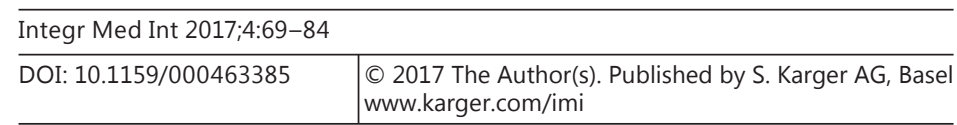

Telles et al.: Yoga: Can It Be Integrated with Treatment of Neuropathic Pain?

A randomized control study comparing the effect of yoga on pain and spinal flexibility in 80 subjects with chronic low-back pain group with a physical exercise group found positive results [85]. The yoga program consisted of physical postures, Pranayama, meditation, and philosophical lessons on yoga for a period of 1 week. The physical exercise group acted as control exercising under the guidance of a trained physiatrist and was matched for time. Researchers administered the Oswestry Disability Index to measure pain-related outcomes, and a goniometer was used to assess spinal flexibility before and after intervention. The yoga group showed a significant decrease in the Oswestry Disability Index scores as compared to the physical exercise group. Furthermore, both groups showed improvement in spinal flexibility, but the yoga group showed greater improvement. Short-term yoga programs can help mitigate pain-related disability and improve the flexibility of the spine.

\section{Case Reports on Yoga as Drivers of Integrative Medicine}

A case study of a 40-year-old male showed how yoga can be used following an SCI [86]. The patient experienced an injury in the thoracic spine (T4-6) in 1978, resulting in paralysis, and since then has been teaching yoga to others who have experienced a similar SCI. He teaches paralysis patients the practice of yoga. Having reduced sensory stimuli, patients suffering from paralysis have clarity of mind and "presence" by experiencing yoga. This "presence" has very real, tangible effects, including being more balanced and grounded, having improved bowel and bladder sensation, being more efficient and powerful in movements, having increased sexual ability and even the possibility of regaining some physiological function. Different asanas, which are extremely relevant to the practice of yoga, are chosen specifically to line up all systems within the body, including digestive, circulatory, immune, etc. This teaching is also known as Iyengar yoga and has greater emphasis on sustained alignment and precision.

A different case study of a gunshot wound victim helps us understand the integration of Iyengar yoga in rehabilitation therapy [87]. The patient experienced injury at the T4 level resulting in paraplegia. Following medical assessment, lyengar yoga was integrated into his rehabilitation therapy to improve his strength, flexibility, relaxation, awareness, and selfreflection. A modified virasana position, supine virasana, and paschimotan asana with the use of props like blankets and bolsters were utilized in the therapy. In a different study, mindfulness was negatively associated with pain catastrophizing in a fear-avoidance model of chronic pain and might be a useful addition to the fear-free model for clinical studies [88].

\section{Management of Pain through Pranayama and SKY}

One of the approaches of yoga is Pranayama, a type of voluntary breathing regulation generally performed with the physical exercise of yoga. There are many different ways to practice Pranayama, but 3 steps to perform it are consistent. There is the inhalation "puraka," the retention of the breath "kumbhaka," and finally the exhalation "rechaka." Regulation of breath in a stepwise manner affects the control of the autonomic nervous system, which has further beneficial effects on different organ systems in the body. When pranayamic breathing is performed with long breath retention, the parasympathetic nervous system is amplified, as demonstrated by the lowering of the metabolic rate and oxygen consumption. On the other hand, with brief breath retention there is an adverse result of augmented oxygen consumption and metabolic rate. Pranayama is a vital component of yoga associated with breathing. In chronic pain, breathing is strained and becomes shallow and uses more thoracic muscles. If the breathing pattern can be corrected with the help of yogic breathing, then certainly it may help in the management of pain. Alterations in neurotransmitters, like serotonin, have a vital 


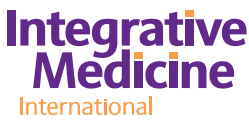

ntegrative
Medicine

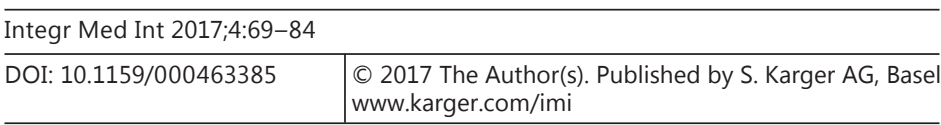

Telles et al.: Yoga: Can It Be Integrated with Treatment of Neuropathic Pain?

action in the NP and have demonstrated interactions with immunocytes [89]. Another study treated NP in patients with diabetic peripheral NP using duloxetine, a selective serotonin and norepinephrine reuptake inhibitor [90]. SKY has also been reported as a useful, low-risk, low-cost alternative for people with depression, anxiety, posttraumatic stress, stress-related medical illnesses, and criminal offenders who are in rehabilitation treatment [91]. Studies also show that Pranayama can be a prescriptive treatment to modulate neurotransmitters. They have demonstrated the beneficial effects of yogic practice which involved Pranayama, meditation, and asana on immune function and the release of stress hormones [92]. The study was randomized, double-blinded, and performed on healthy volunteers from a university. The authors analyzed the immune-related cytokines in serum or plasma, in addition to oxidative stress, antioxidant components, and stress hormones. They found that yogic practice had markedly raised the level of immune-related cytokines in serum, which included interleukin-12 and interferon- $\gamma$, and low levels of adrenalin in plasma along with enhanced levels of serotonin in plasma when compared to the control group who were not involved in any kind of exercise. Thus, they concluded that regular practice of yoga will reduce oxidative stress and improve antioxidant levels in addition to reducing the release of stress hormones and improving the immune system. SKY is a cyclic controlled breathing practice, which includes Ujjayi, Bhastrika, and Om chanting. This breathing practice also has a role in alleviating pain involved in the pathology of certain diseases. One study demonstrated that SKY and Pranayama act as an effective intervention for decreasing stress and pain among patients with advanced-stage breast cancer [93]. This study was based on 147 female participants who were randomized into 2 groups: a yoga group $(n=78)$ and a standard group $(n=69)$. The yoga group performed exercise for $18 \mathrm{~h}$ over 3 days, and then they had to practice it daily for $20 \mathrm{~min}$ at home. The results showed a significant difference in the blood cortisol levels after 3 months of practice. Pain perception, as measured on a $0-10$ verbal scale of pain, was reduced by 3 points in the yoga group as compared to the standard group. This showed the effectiveness of the Pranayama and SKY exercise in patients suffering from advanced stages of cancer. However, the direct role of SKY in NP needs to be evaluated.

\section{Do Breathing Exercises Enhance Stem Cell Migration to Treat NP?}

NP shows scarce response to the conventional drug therapies, thus requiring novel approaches to combat the limitations of a previous therapy. Stem cells may be one approach to alleviate the limitations of current therapies. By production of brief intermittent hypoxia through Pranayama, migration of the stem cells from their niche has not been explored, and therefore it cannot be ruled out whether it contributes to the alleviation of NP, which needs comprehensive investigation [94, 95]. Pathogenesis and maintenance of NP is due to the interactions between the neurons, pro- and anti-inflammatory cytokines, glial cells, and inflammatory immune cells [43]. Different stem cell treatments with stem cells of different origin have been studied for treating NP induced in experimental animal models.

\section{Search Strategy}

Databases and Online Search Terms

The bibliography databases that were searched to compile the review included PubMed, Scopus, Science Direct, and Google Scholar. The keywords used in the search included: [yoga] AND [Neuropathic Pain], [yoga] AND chronic pain, Neuropathic pain [(mechanism OR pathway)], [SKY] AND pain, [(Spinal cord injury OR Yoga)], etc. 


\section{Integrative Medicine

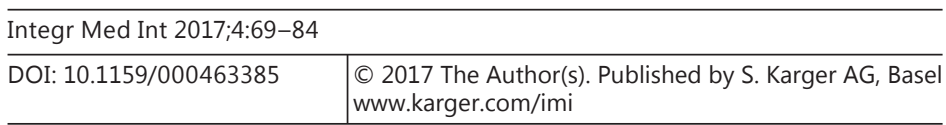

Telles et al.: Yoga: Can It Be Integrated with Treatment of Neuropathic Pain?

\section{Conclusion}

The above-mentioned studies have shown the role of $\mathrm{NKCC}^{-\mathrm{Cl}^{-}}$protein in SCI-induced NP rat model by involving kinase WNK1, which indicates the implication of ionic channel/ gate in pain perception. Similarly, the increased expression levels of MMPs in SCI-induced animal models are mediated through the wht signaling process. Moreover, P2X4 is one of the pain-sensing proteins which transmit the signaling process in pain perception mediated by p38MAPK by interacting with the P2X4 receptor. ATP receptor induces the P2X4 protein to carry out the process. Various cannabinoid molecules and their receptors have also been shown to have significance in pain, examined through various animal models. Similarly, B1 and TRPV-1 receptors have also been found to be increased twofold in a TH model. The role of BDNF has been studied in animal models of pain. It is well established that yogic practice influences the sympathetic nervous system and hypothalamic-pituitary-adrenal axis [96]. Further, yoga is believed to modulate the action of nitric oxide release/endothelial function, endogenous endocannabinoids, and opiates [97]. Although the molecular effects of yoga on various pathological conditions are not well established [98], we have attempted to pave way for future study designs that examine their relation to NP.

Modern prescriptive treatment strategies and reductionist therapeutic approaches, pertaining to a few or most of the systemic and psychological disorders, have various metabolic side effects. The use of yoga will help to cope with these well-defined side effects and will boost the quality of health care. Overall, the simplicity and practicality of yoga make it a viable therapy that should be utilized in rehabilitation centers or clinics in order to help ameliorate NP [6, 7, 17-19].

\section{Acknowledgement}

We sincerely acknowledge Dominic Schomberg for editing the manuscript.

\section{Disclosure Statement}

To best of our knowledge, no conflict of interests exists.

\section{Author Contributions}

Editing and critical review of the manuscript: Shirley Telles. Writing of the manuscript: Natasha Sayal, Carrie Nacht, Abhishek Chopra, Kush Patel, Alice Wnuk, Priya Dalvi, Kulsajan Bhatia. Editing and conceptualization of the manuscript: Akshay Anand and Gurwattan Miranpuri.

\section{References}

1 National Spinal Cord Injury Statistical Center: Spinal Cord Injury Facts and Figures at a Glance. Birmingham, National Spinal Cord Injury Statistical Center, 2016.

-2 Barrett H, McClelland JM, Rutkowski SB, Siddall PJ: Pain characteristics in patients admitted to hospital with complications after spinal cord injury. Arch Phys Med Rehab 2003;84:789-795.

-3 Finnerup NB, Otto M, Jensen TS, Sindrup SH: An evidence-based algorithm for the treatment of neuropathic pain. MedGenMed 2007;9:36.

4 Cardenas DD, Jensen MP: Treatments for chronic pain in persons with spinal cord injury: a survey study. J Spinal Cord Med 2006;29:109. 
Telles et al.: Yoga: Can It Be Integrated with Treatment of Neuropathic Pain?

$>5$ may provide a mechanism that explains how slow deep breathing shifts the autonomic nervous system. Med Hypotheses 2006;67:566-571.

-19 Buffart LM, Van Uffelen JG, Riphagen II, Brug J, van Mechelen W, Brown WJ, Chinapaw MJ: Physical and psychosocial benefits of yoga in cancer patients and survivors, a systematic review and meta-analysis of randomized controlled trials. BMC Cancer 2012;12:1.

20 Blank S, Kittel J, Haberman M: Active practice of Iyengar yoga as an intervention for breast cancer survivors. Int J Yoga Ther 2005;15:51-59.

-21 Carson JW, Carson KM, Porter LS, Keefe FJ, Seewaldt VL: Yoga of awareness program for menopausal symptoms in breast cancer survivors: results from a randomized trial. Support Care Cancer 2009;17:1301-1309.

22 Galantino ML, Cannon N, Hoelker T, Iannaco J, Quinn L: Potential benefits of walking and yoga on perceived levels of cognitive decline and persistent fatigue in women with breast cancer. Rehab 0ncol 2007;25:3.

-23 Galantino ML, Bzdewka TM, Eissler-Russo JL, Holbrook ML: The impact of modified Hatha yoga on chronic low back pain: a pilot study. Alternat Ther Health Med 2004;10:56.

-24 Sherman KJ, Cherkin DC, Erro J, Miglioretti DL, Deyo RA: Comparing yoga, exercise, and a self-care book for chronic low back pain: a randomized, controlled trial. Ann Intern Med 2005;143:849-856.

-25 Bushnell M, Case L, Ceko M, Cotton V, Gracely J, Low L, Pitcher M, Villemure C: Effect of environment on the long-term consequences of chronic pain. Pain 2015;156:S42.

-26 Matsuzawa-Yanagida K, Narita M, Nakajima M, Kuzumaki N, Niikura K, Nozaki H, Takagi T, Tamai E, Hareyama $\mathrm{N}$, Terada M: Usefulness of antidepressants for improving the neuropathic pain-like state and pain-induced anxiety through actions at different brain sites. Neuropsychopharmacology 2008;33:1952-1965.

27 Miller LR, Cano A: Comorbid chronic pain and depression: who is at risk? J Pain 2009;10:619-627.

-28 Wallace VC, Segerdahl AR, Blackbeard J, Pheby T, Rice AS: Anxiety-like behaviour is attenuated by gabapentin, morphine and diazepam in a rodent model of HIV anti-retroviral-associated neuropathic pain. Neurosci Lett 2008;448:153-156.

-29 Seminowicz DA, Laferriere AL, Millecamps M, Jon S, Coderre TJ, Bushnell MC: MRI structural brain changes associated with sensory and emotional function in a rat model of long-term neuropathic pain. Neuroimage 2009;47:1007-1014.

-30 Summers JD, Rapoff MA, Varghese G, Porter K, Palmer RE: Psychosocial factors in chronic spinal cord injury pain. Pain 1991;47:183-189.

-31 Vachon P, Millecamps M, Low L, Thompsosn SJ, Pailleux F, Beaudry F, Bushnell CM, Stone LS: Alleviation of chronic neuropathic pain by environmental enrichment in mice well after the establishment of chronic pain. Behav Brain Funct 2013;9:1.

-32 Ji R-R, Xu Z-Z, Gao Y-J: Emerging targets in neuroinflammation-driven chronic pain. Nat Rev Drug Discov 2014; 13:533-548.

-33 Kumar SP, Saha S: Mechanism-based classification of pain for physical therapy management in palliative care: a clinical commentary. Indian J Palliative Care 2011;17:80.

-34 Fields HL: Should we be reluctant to prescribe opioids for chronic non-malignant pain? Pain 2007;129:233234.

-35 Chou R, Huffman LH: Nonpharmacologic therapies for acute and chronic low back pain: a review of the evidence for an American Pain Society/American College of Physicians clinical practice guideline. Ann Intern Med 2007;147:492-504.

-36 Schomberg D, Miranpuri G, Duellman T, Crowell A, Vemuganti R, Resnick D: Spinal cord injury induced neuropathic pain: molecular targets and therapeutic approaches. Metab Brain Dis 2015;30:645-658.

-37 Ahmed MM, Lee H, Clark Z, Miranpuri GS, Nacht C, Patel K, Liu L, Joslin J, Kintner D, Resnick DK: Pathogenesis of spinal cord injury induced edema and neuropathic pain: expression of multiple isoforms of wnk1. Ann Neurosci 2014;21:97. 
Telles et al.: Yoga: Can It Be Integrated with Treatment of Neuropathic Pain?

-38 Kim HT, Kim T, Novotny B, Khan N, Aksamit J, Siegel S, Miranpuri GS, Resnick DK: Thermal hyperalgesia assessment for rats after spinal cord injury: developing a valid and useful pain index. Spine J 2014;14:984989.

39 Lee HK, Ahmed MM, King KC, Miranpuri GS, Kahle KT, Resnick DK, Sun D: Persistent phosphorylation of NKCC1 and WNK1 in the epicenter of the spinal cord following contusion injury. Spine J 2014;14:777-781.

-40 Miranpuri GS, Schomberg DT, Alrfaei B, King KC, Rynearson B, Wesley VS, Khan N, Obiakor K, Wesley UV, Resnick DK: Role of matrix metalloproteinases 2 in spinal cord injury-induced neuropathic pain. Ann Neurosci 2016;23:25-32.

-41 Krueger EM, Miranpuri GS, Resnick DK: Emerging role of WNK1 in pathologic central nervous system signaling. Ann Neurosci 2011;18:70-75.

-42 Hasbargen T, Ahmed MM, Miranpuri G, Li L, Kahle KT, Resnick D, Sun D: Role of NKCC1 and KCC2 in the development of chronic neuropathic pain following spinal cord injury. Ann NY Acad Sci 2010;1198:168-172.

-43 Cramer SW, Baggott C, Cain J, Tilghman J, Allcock B, Miranpuri G, Rajpal S, Sun D, Resnick D: The role of cationdependent chloride transporters in neuropathic pain following spinal cord injury. Mol Pain 2008;4:1.

44 Kawasaki Y, Xu Z-Z, Wang X, Park JY, Zhuang Z-Y, Tan P-H, Gao Y-J, Roy K, Corfas G, Lo EH: Distinct roles of matrix metalloproteases in the early-and late-phase development of neuropathic pain. Nat Med 2008;14: 331-336.

45 Inoue K, Tsuda M, Koizumi S: ATP receptors in pain sensation: involvement of spinal microglia and P2X4 receptors. Purinergic Signal 2005;1:95-100.

46 Tsuda M, Inoue K, Salter MW: Neuropathic pain and spinal microglia: a big problem from molecules in "small" glia. Trends Neurosci 2005;28:101-107.

-47 Tsuda M, Shigemoto-Mogami Y, Koizumi S, Mizokoshi A, Kohsaka S, Salter MW, Inoue K: P2X4 receptors induced in spinal microglia gate tactile allodynia after nerve injury. Nature 2003;424:778-783.

-48 Hama A, Sagen J: Behavioral characterization and effect of clinical drugs in a rat model of pain following spinal cord compression. Brain Res 2007;1185:117-128.

49 Kinsey SG, Long JZ, O’Neal ST, Abdullah RA, Poklis JL, Boger DL, Cravatt BF, Lichtman AH: Blockade of endocannabinoid-degrading enzymes attenuates neuropathic pain. J Pharmacol Exp Ther 2009;330:902-910.

-50 DomBourian MG, Turner NA, Gerovac TA, Vemuganti R, Miranpuri GS, Türeyen K, Satriotomo I, Miletic V, Resnick DK: B1 and TRPV-1 receptor genes and their relationship to hyperalgesia following spinal cord injury. Spine 2006;31:2778-2782.

51 Wu J, Renn CL, Faden AI, Dorsey SG: TrkB.T1 contributes to neuropathic pain after spinal cord injury through regulation of cell cycle pathways. J Neurosci 2013;33:12447-12463.

52 Ji R-R, Berta T, Nedergaard M: Glia and pain: is chronic pain a gliopathy? Pain 2013;154:S10-S28.

-53 Zhang Z-J, Cao D-L, Zhang X, Ji R-R, Gao Y-J: Chemokine contribution to neuropathic pain: respective induction of CXCL1 and CXCR2 in spinal cord astrocytes and neurons. Pain 2013;154:2185-2197.

54 Gao Y-J, Ji R-R: Chemokines, neuronal-glial interactions, and central processing of neuropathic pain. Pharmacol Ther 2010;126:56-68.

-55 Chen G, Park C-K, Xie R-G, Berta T, Nedergaard M, Ji R-R: Connexin-43 induces chemokine release from spinal cord astrocytes to maintain late-phase neuropathic pain in mice. Brain 2014;137:2193-2209.

56 Sorkin L, Svensson CI, Jones-Cordero TL, Hefferan MP, Campana WM: Spinal p38 mitogen-activated protein kinase mediates allodynia induced by first-degree burn in the rat. J Neurosci Res 2009;87:948-955.

-57 Tan Y-H, Li K, Chen X-Y, Cao Y, Light AR, Fu K-Y: Activation of Src family kinases in spinal microglia contributes to formalin-induced persistent pain state through p38 pathway. J Pain 2012;13:1008-1015.

-58 Weisshaar CL, Dong L, Bowman AS, Perez FM, Guarino BB, Sweitzer SM, Winkelstein BA: Metabotropic glutamate receptor-5 and protein kinase C-epsilon increase in dorsal root ganglion neurons and spinal glial activation in an adolescent rat model of painful neck injury. J Neurotrauma 2010;27:2261-2271.

-59 Villemure C, Čeko M, Cotton VA, Bushnell MC: Insular cortex mediates increased pain tolerance in yoga practitioners. Cereb Cortex 2014;24:2732-2740.

60 Lee M, Moon W, Kim J: Effect of yoga on pain, brain-derived neurotrophic factor, and serotonin in premenopausal women with chronic low back pain. Evid Based Complement Alternat Med 2014;2014;203173.

-61 Curtis K, Osadchuk A, Katz J: An eight-week yoga intervention is associated with improvements in pain, psychological functioning and mindfulness, and changes in cortisol levels in women with fibromyalgia. J Pain Res 2011;4:189-201.

62 Vallath N: Perspectives on Yoga inputs in the management of chronic pain. Indian J Palliat Care 2010;16:1.

63 Kim S-S, Min W-K, Kim J-H, Lee B-H: The effects of VR-based Wii Fit Yoga on physical function in middle-aged female LBP patients. J Phys Ther Sci 2014;26:549-552.

64 Bushnell MC, Čeko M, Low LA: Cognitive and emotional control of pain and its disruption in chronic pain. Nat Rev Neurosci 2013;14:502-511.

-65 Zhang N, Yin Y, Xu S-J, Wu Y-P, Chen W-S: Inflammation \& apoptosis in spinal cord injury. Indian J Med Res 2012;135:287.

-66 Smith EN, Boser A: Yoga, vertebral fractures, and osteoporosis: research and recommendations. Int J Yoga Ther 2013;23:17-23.

67 Zwick D, Dunn M: Integrating Iyengar yoga into rehabilitation. Nursing 2007;37:10-12.

68 Balasubramaniam M, Telles S, Doraiswamy PM: Yoga on our minds: a systematic review of yoga for neuropsychiatric disorders. Front Psychiatry 2013;3:117. 
Telles et al.: Yoga: Can It Be Integrated with Treatment of Neuropathic Pain?

-69 Büssing A, Ostermann T, Lüdtke R, Michalsen A: Effects of yoga interventions on pain and pain-associated disability: a meta-analysis. J Pain 2012;13:1-9.

70 Chiesa A, Serretti A: Mindfulness-based interventions for chronic pain: a systematic review of the evidence. J Alternat Complement Med 2011;17:83-93.

71 Kennedy P, Duff J: Post traumatic stress disorder and spinal cord injuries. Spinal Cord 2001;39:1-10.

-72 Telles S, Naveen K, Dash M: Yoga reduces symptoms of distress in tsunami survivors in the Andaman islands. Evid Based Complement Alternat Med 2007;4:503-509.

-73 Descilo T, Vedamurtachar A, Gerbarg P, Nagaraja D, Gangadhar B, Damodaran B, Adelson B, Braslow L, Marcus $S$, Brown R: Effects of a yoga breath intervention alone and in combination with an exposure therapy for posttraumatic stress disorder and depression in survivors of the 2004 South-East Asia tsunami. Acta Psychiatr Scand 2010;121:289-300.

74 Kjaer TW, Bertelsen C, Piccini P, Brooks D, Alving J, Lou HC: Increased dopamine tone during meditationinduced change of consciousness. Cogn Brain Res 2002;13:255-259.

-75 Streeter CC, Whitfield TH, Owen L, Rein T, Karri SK, Yakhkind A, Perlmutter R, Prescot A, Renshaw PF, Ciraulo DA: Effects of yoga versus walking on mood, anxiety, and brain GABA levels: a randomized controlled MRS study. J Alternat Complement Med 2010;16:1145-1152.

76 Pal R, Singh SN, Chatterjee A, Saha M: Age-related changes in cardiovascular system, autonomic functions, and levels of BDNF of healthy active males: role of yogic practice. Age 2014;36:1-17.

-77 Murthy PNV, Gangadhar B, Janakiramaiah N, Subbakrishna D: Normalization of P300 amplitude following treatment in dysthymia. Biol Psychiatry 1997;42:740-743.

-78 Kjellgren A, Bood SÅ, Axelsson K, Norlander T, Saatcioglu F: Wellness through a comprehensive Yogic breathing program - a controlled pilot trial. BMC Complement Alternat Med 2007;7:1.

79 Naveen G, Thirthalli J, Rao M, Varambally S, Christopher R, Gangadhar B: Positive therapeutic and neurotropic effects of yoga in depression: a comparative study. Indian J Psychiatry 2013;55:400.

-80 Tilbrook HE, Cox H, Hewitt CE, Kang' ombe AR, Chuang L-H, Jayakody S, Aplin JD, Semlyen A, Trewhela A, Watt I: Yoga for chronic low back pain: a randomized trial. Ann Intern Med 2011;155:569-578.

-81 Sherman KJ, Cherkin DC, Wellman RD, Cook AJ, Hawkes RJ, Delaney K, Deyo RA: A randomized trial comparing yoga, stretching, and a self-care book for chronic low back pain. Arch Intern Med 2011;171:2019-2026.

82 Frank JW, Bair MJ, Becker WC, Krebs EE, Liebschutz JM, Alford DP: Update in pain medicine for primary care providers: a narrative review, 2010-2012. Pain Med 2014;15:425-431.

83 Wren AA, Wright MA, Carson JW, Keefe FJ: Yoga for persistent pain: new findings and directions for an ancient practice. Pain 2011;152:477.

84 Hill JC, Whitehurst DG, Lewis M, Bryan S, Dunn KM, Foster NE, Konstantinou K, Main CJ, Mason E, Somerville S: Comparison of stratified primary care management for low back pain with current best practice (STarT Back): a randomised controlled trial. Lancet 2011;378:1560-1571.

-85 Tekur P, Chametcha S, Hongasandra RN, Raghuram N: Effect of yoga on quality of life of CLBP patients: a randomized control study. Int J Yoga 2010;3:10.

86 Johnson L: How yoga helps me. Matthew Sanford, January 2007. Adapted from an article that appeared in the April 2007 Paraplegia News. http://www.healingtherapies.info/Yoga\&SCI.htm.

87 Iyengar BKS: Light on Yoga. New York, Schocken, 1965.

88 Schütze R, Rees C, Preece M, Schütze M: Low mindfulness predicts pain catastrophizing in a fear-avoidance model of chronic pain. Pain 2010;148:120-127.

89 Urtikova N, Berson N, Van Steenwinckel J, Doly S, Truchetto J, Maroteaux L, Pohl M, Conrath M: Antinociceptive effect of peripheral serotonin 5-HT 2B receptor activation on neuropathic pain. Pain 2012;153:1320-1331.

-90 Raskin J, Pritchett YL, Wang F, D’Souza DN, Waninger AL, Iyengar S, Wernicke JF: A double-blind, randomized multicenter trial comparing duloxetine with placebo in the management of diabetic peripheral neuropathic pain. Pain Med 2005;6:346-356.

-91 Zope SA, Zope RA: Sudarshan kriya yoga: breathing for health. Int J Yoga 2013;6:4.

$\$ 92$ Lim S-A, Cheong K-J: Regular yoga practice improves antioxidant status, immune function, and stress hormone releases in young healthy people: a randomized, double-blind, controlled pilot study. J Alternat Complement Med 2015;21:530-538.

-93 Kumar N, Bhatnagar S, Velpandian T, Patnaik S, Menon G, Mehta M, Kashyap K, Singh V: Randomized controlled trial in advance stage breast cancer patients for the effectiveness on stress marker and pain through Sudarshan Kriya and Pranayam. Indian J Palliat Care 2013;19:180.

94 Shree N, Bhonde RR: Can yoga therapy stimulate stem cell trafficking from bone marrow? J Ayurveda Integr Med 2016; 7:181-184.

95 Malshe PC: Nisshesha rechaka pranayama offers benefits through brief intermittent hypoxia. Ayu 2011;32: 451.

$\$ 96$ Vera FM, Manzaneque JM, Maldonado EF, Carranque GA, Rodriguez FM, Blanca MJ, Morell M: Subjective sleep quality and hormonal modulation in long-term yoga practitioners. Biol Psychol 2009;81:164-168.

97 Michalsen A, Grossman P, Acil A, Langhorst J, Lüdtke R, Esch T, Stefano G, Dobos G: Rapid stress reduction and anxiolysis among distressed women as a consequence of a three-month intensive yoga program. Med Sci Monit 2005;11:CR555-CR561.

$\$ 98$ Sutar R, Yadav S, Desai G: Yoga intervention and functional pain syndromes: a selective review. Int Rev Psychiatry 2016;28:316-322. 